\title{
The Effect of Partial Removable Denture Use on Oral Health Related Quality of Life and Masticatory Function, after 5 Years Use
}

\author{
Mantshumba Milolo Augustin ${ }^{1}$, Duyck Joke², Sekele Isouradi Bourleyi ${ }^{1}$, Lutula Pene Shenda1, \\ Nyimi Bushabu Fidele ${ }^{3,4}$, Tshombe Mulamba Van ${ }^{5}$, Ntumba Mulumba Kanda1, Ignace Naert ${ }^{2}$
}

\author{
${ }^{1}$ Prosthodontics and Orthodontics Service, Affiliated Hospital of Kinshasa University, Kinshasa, DR Congo \\ ${ }^{2}$ Department of Oral Health Sciences, Prosthetics Section, Katholieke Universiteit Leuven, Leuven, Belgium \\ ${ }^{3}$ Department of Oral and Maxillofacial Surgery, Second Affiliated Hospital of Jiamusi University, Jiamusi, China \\ ${ }^{4}$ Affiliated Hospital of Kinshasa University, Kinshasa, DR Congo \\ ${ }^{5}$ Laboratory Center of Research Nuclear of Kinshasa University, Kinshasa, DR Congo \\ Email: ^augustinmantshumba@gmail.com
}

How to cite this paper: Augustin, M.M., Joke, D., Bourleyi, S.I., Shenda, L.P., Fidele, N.B., Van, T.M., Kanda, N.M. and Naert, I. (2016) The Effect of Partial Removable Denture Use on Oral Health Related Quality of Life and Masticatory Function, after 5 Years Use. Open Journal of Stomatology, 6, 201210.

http://dx.doi.org/10.4236/ojst.2016.610026

Received: August 27, 2016

Accepted: October 21, 2016

Published: October 24, 2016

Copyright $\odot 2016$ by authors and Scientific Research Publishing Inc. This work is licensed under the Creative Commons Attribution International License (CC BY 4.0).

http://creativecommons.org/licenses/by/4.0/

\begin{abstract}
The aim of this study was to evaluate whether partial removable denture use indeed leads to improved oral health related quality of life and masticatory function. Materials and Methods: Partially edentulous patients presenting for removable denture treatment at the Prosthodontics Service in the Hospital Affiliated to Kinshasa University (Democratic Republic of Congo) were assessed for enrolment in this study. After applying exclusion criteria, 378 patients were included in the study, and randomly assigned into 2 groups. Oral health related quality of life (OHIP-23) and mastication time $(\mathrm{MaT})$, number of chewing cycles $(\mathrm{MaC})$, mastication frequency $(\mathrm{MaF})$, and the sizes of the peanut fragments (FraS) were compared in both groups. Statistical significance was set at $\mathrm{p}<0.05$. Results: The average MaC, MaT, MaF, and FraS were 119 ( \pm SD 53.70), $86.75( \pm$ SD 35.35), $1.38( \pm$ SD 0.25), and $3.3( \pm$ SD 3.25) for the denture group and $77.9( \pm$ SD 23.9), $60.2( \pm$ SD 17.91), 1.29 ( \pm SD 0.15), and 1.5 $( \pm$ SD 0.7$)$ for the non-denture group, respectively. Conclusion: The overall oral health related quality of life was best in the non-denture than denture.
\end{abstract}

\section{Keywords}

Partial Removable Denture Acrylic Resin, Mastication, and Oral Health Related Quality of Life

\section{Introduction}

Mastication, the first step of digestion, is defined as a process by which the food placed 
in the mouth is mechanically modified to make it suitable for swallowing [1]. The teeth are essential for grinding food and to prepare the food bolus for digestion, the tooth loss leads to impair mastication function [2] and sufficient antagonistic tooth contact is required to chew food [3].

In early days, there was a tendency to replace all missing teeth [4]; however, it's generally accepted that it is not required to replace all teeth to restore oral function. The shortened denture arch concept is well documented since its introduction by Kayser A.F. et al., Gotfredsen K. et al., Kanno T. et al., twelve anterior teeth and eight posterior teeth are necessary and sufficient to ensure the mandibular stability required for a good mastication provided that the teeth are effective [5] [6] [7]. A study of Gerritsen, Witter et al. indicates that a shortened dental arch is a sustainable solution for partially edentulous patients, as they report that $87 \%$ of the patients with shortness dental arcade (SDA) were still in the same condition after more time than 40 years of function [8].

All oral diseases, which affect the number, structure and position of the teeth are supposed to have an impact on the quality of life, on the mastication and consequently on the nutrition [9] [10]. Replacing lost teeth by means of a removable denture is expected to improve mastication and thereby nutrition. The other authors indeed found an improved ability to reduce the bolus particle size when using partial removable denture, although the masticatory function and the teeth's sensory function [11] could not be re-established completely. Also applies to other studies, however, indicate that oral rehabilitation by means of partial denture does not lead to improved energy and nutrient intake [12] [13]. These results attenuate the association of mastication with food and/or nutritional intake and indicate that mastication alone cannot explain food and/or nutrient intake. If food choice was exclusively influenced by impaired mastication, the provision of dentures to partially edentulous persons would improve their diet. However, intervention studies have not shown any significant effects even after the provision of new prosthesis. It is assumed that oral health, particularly masticatory function, may contribute to the food selection of elderly people.

One of the main objectives of the oral rehabilitation with acrylic partial removable denture is to improve the masticatory function by replacing the missing teeth [14]. Besides the uncertainty about its effect on oral function, partial denture treatment also holds risks for the remaining dentition. The recent study of Jepson N.J et al. showed that, removable partial dentures (RPDs) have the potential to negatively impact different aspects of oral health [15]. Furthermore, there are very few studies [16] that have investigated whether the RPDs have any impact on general health. From the limited literature available, it appears that RPDs can possibly improve quality of life, and this is relevant in the era of patient-centered care.

Studies have examined the effects of the fixed prosthesis and implants on masticatory function [17], but the physiological impact of the rehabilitation by partial removable prosthesis has poorly been studied and the outcomes are not straightforward [10]. And no study found has been assessed the objective OHIP except the preliminary study of Sekele that has been assessed the subjective OHIP in two-year function of RDP [18]. 
The aim of this study was therefore to evaluate the effect of partial removable denture treatment on oral health related quality of life and masticatory function after 5 years of function.

\section{Materials and Methods}

It's an interventional prospective study of all partially edentulous patients (except patients with class 4 of Kennedy) presenting for removable denture treatment at the Prosthodontics Service in the Hospital Affiliated to Kinshasa University, Democratic Republic of Congo between May 2008 to August 2008, were assessed in this study. Criteria for exclusion were joint diseases $(n=22)$, hematological diseases $(n=3)$, allergies $(n=19)$, current or history of chemotherapy and radiotherapy $(n=1)$, on a special diet prescribed by a physician $(\mathrm{n}=17)$, a DPSI equal to or above 2 after oral hygiene instructions $(n=20)$, carious or infection of endodontic teeth $(n=25)$, and unwilling to participate in the study due to refusal to be without prosthesis when selected to be in the non-denture group. After this applying exclusion criteria and after receiving oral hygiene instructions and providing informed consent, 379 patients (between 19 to 89 years old) were included in the study. They were randomly assigned into 2 groups. One group of patients received a removable acrylic denture (denture group, $n=189$ ) than the other group did not (non-denture group, $\mathrm{n}=189$ ). After five years of function, 138 patients were still in the study (60 for the denture group and 78 for the non-denture group). 241 participants lost to follow-up: dropped out because they moved to another town $(n=24)$, because they did not respond to the recall invitation $(n=181)$, because of a changed oral status $(n=24)$, and due to death $(n=12)$. It was after informed consent of patients and obtained an ethical committee from the School of health of medicine faculty of Kinshasa University number ESP/CE/018 bis/2009 du 09 Jun 2009 that the study started [19].

\subsection{Oral Health Related Quality of Life}

Oral health related quality of life was evaluated using the OHIP-23 [20] [21] and adapted on the African context. Each question had to be answered by yes or no, depending on whether the participants was satisfied (outcome $=1$ ) or dissatisfied (outcome $=0$ ) about a specific aspect of his or her oral health related quality of life. The overall oral health related quality of life per participant was represented by the sum of the outcomes of the individual questions. The questions are similar for both groups, although the formulation of the questions was according to the participants' oral condition (wearing a denture or not).

\subsection{Masticatory Function}

Mastication kinetics was evaluated by measuring the mastication time (MaT), number of chewing cycles $(\mathrm{MaC})$, and mastication frequency $(\mathrm{MaF}=\mathrm{MaC} / \mathrm{MaT})$ required to chew 5 grams of roasted peanuts until it was considered appropriate for swallowing. The test was performed twice per participant and Video recording was used for the 
evaluation of kinetic parameters of the mastication, also the time of each sequence of chewing. A stopwatch and the number of cycles was counted by two independent investigators. Instead of swallowing, the participants were asked to spit the chewed peanuts in a cup and the participants were asked to rinse with water several times to clear the mouth. Also the rinsing water was collected in the cup. The sizes of the peanut fragments (FraS) were measured in $\mathrm{mm}$ and used to evaluate mastication efficacy. Particle size analyses were performed at the central laboratory of nuclear research of Kinshasa University. The crushed food or homogenates was separated from the supernatant and was left in the open air for dissecation in 48 hours before the sifting. The homogenates were passed through a decreasing sieve mesh column $5.6 \mathrm{~mm}, 4 \mathrm{~mm}, 2$ $\mathrm{mm}, 1 \mathrm{~mm}, 0.5 \mathrm{~mm}, 0.25 \mathrm{~mm}$ and $0.125 \mathrm{~mm}$ (Retsh AS 200, Retsh GmbH, Haan, Germany) (Figure 1). The homogenates were sifted in the laboratory under vibrator that was adjusted so standardized to its maximum power for a period of one minute.

After each sifting, the content of each sieve was weighed with an analytical balance (Sartorius model CPA225D, Sartorius GmbH, Goettingen, Germany), with a sensitivity of $0.00001 \mathrm{~g}$.

The outcome variables of OHIP, MaT, MaC, MaF, and FraS in the denture and nondenture group were compared using ANOVA (SPSS 20.0, Inc, and Chicago, IL, U.S.A). Statistical significance was set at $\mathrm{p}<0.05$.

\section{Results}

The average age in this study in denture group and no-denture-group was $53.15 \pm 22.05$ and $31.59 \pm 11.98$ years. Women have been more participated than the men in both groups with respectively $36(60 \%)$ and $50(64 \%)$ (Table 1). In the denture and the non-denture group, 24 and 21 patients had a Kennedy Class 1 edentulism, 12 and 18 patients had a Kennedy Class 2 edentulism, and 24 and 39 patients had a Kennedy Class III edentulism respectively. The result from OHIP-23 variable showed that the participants enrolled in the non-denture-group were most satisfied on the oral health related quality of life than the denture-group by affected appearance, respiration, the bad taste, taking food, having pain in jaw, eating pain, dental pain and anxiety. However, there are some non-significant differences between these two groups for the appearance ( $p=$
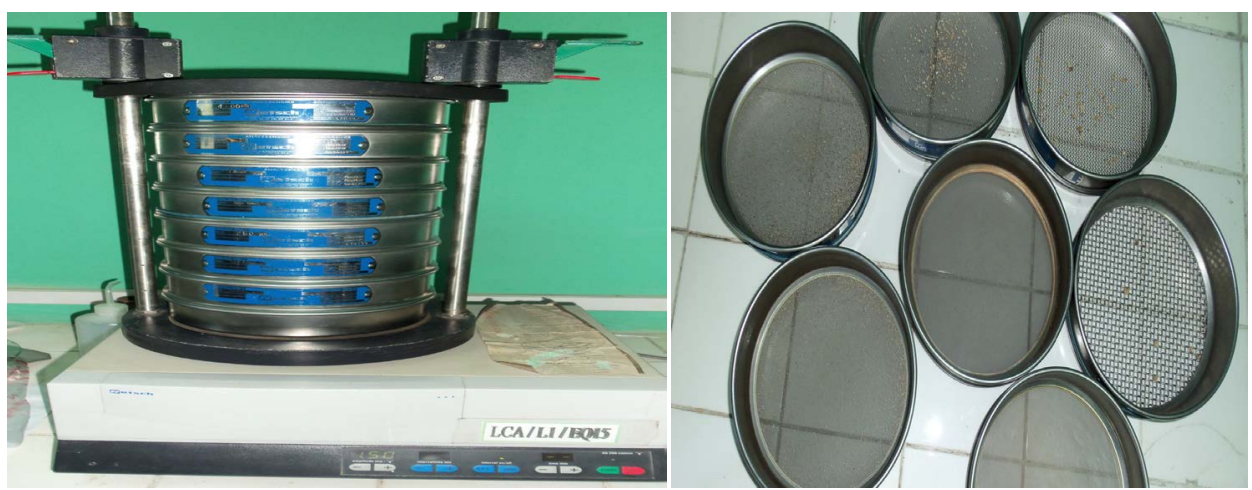

Figure 1. Sieves image. 
Table 1. Masticatory parameters according to gender in both groups.

\begin{tabular}{ccccccc}
\hline & Gender & $\begin{array}{c}\text { Number of } \\
\text { participants } \\
(\%)\end{array}$ & $\begin{array}{c}\text { MaC } \\
(\text { number }) \\
(\mathrm{SD})\end{array}$ & $\begin{array}{c}\text { MaT (seconds) } \\
(\mathrm{SD})\end{array}$ & $\begin{array}{c}\mathrm{MaF}(\mathrm{Hz}) \\
(\mathrm{SD})\end{array}$ & $\begin{array}{c}\text { FraS (mm) } \\
(\mathrm{SD})\end{array}$ \\
\hline $\begin{array}{c}\text { Denture-group } \\
(\mathrm{n}=60)\end{array}$ & Men & $24(40)$ & $137(47.47)$ & $102.62(42.17)$ & $1.37(0.20)$ & $3.3(3.25)$ \\
& Women & $36(60)$ & $107(56.17)$ & $74.5(24.30)$ & $1.3(0.30)$ & $3.3(3.25)$ \\
\hline $\begin{array}{c}\text { Non-denture } \\
\text { group (n=78) }\end{array}$ & Men & $28(36)$ & $80.85(20.11)$ & $60.2(17.13)$ & $1.29(0.16)$ & $1.5(0.70)$ \\
& Women & $50(64)$ & $76.30(26.38)$ & $60.5(18.48)$ & $1.24(0.15)$ & $1.5(0.70)$ \\
\hline
\end{tabular}

Legend: $\mathrm{MaC}=$ number of mastication cycles, $\mathrm{MaT}=$ mastication time, $\mathrm{MaF}=$ mastication frequency, and FraS = peanut fragment size in $\mathrm{mm}$.

$0.3)$, bad taste $(\mathrm{p}=0.3)$, pain during the dinner $(\mathrm{p}=0.4)$, anxiety or unrest $(\mathrm{p}=0.1)$, physical disability with diminished taste $(\mathrm{p}=0.3)$, dental brushing $(\mathrm{p}=0.3)$, avoid to eat $(\mathrm{p}=0.2)$, diet $(\mathrm{p}=0.3)$, not easy at repast $(\mathrm{p}=0.3)$ and $\mathrm{p}=0.2$ for avoid to laugh (Table 2).

\section{Mastication Kinetics}

The masticatory cycle of denture-group was higher compared by non-denture-group, the same to gender variable with $137 \pm 47.47$ and $107 \pm 56.17$, against $80.85 \pm 20.11$ and $76.30 \pm 26.38$ for the non-denture-group respectively. But in the non-denture group, the mastication time for women was longer than men (Table 1).

Table 3 showed that, the distribution of $\mathrm{MaC}, \mathrm{MaT}, \mathrm{MaF}$, and $\mathrm{FraS}$ were increased in denture than non-denture. The increasing distribution of $\mathrm{MaC}$ in both group was depending to the number of occluding pairs, but FraS was not depending on the number of occluding pairs in denture than non-denture group. The average FraS was significantly lower for the denture $3.3( \pm \mathrm{SD} 3.25)$ compared to the non-denture group 1.5 $( \pm S D 0.70) \mathrm{mm},(\mathrm{p}=0.02)$. These changes were independent of gender, age, occluding pairs. On Kennedy classification; only the class 3 of Kennedy showed a masticatory efficiency by giving small fragments size with $0.75( \pm$ SD $0.35 \mathrm{~mm})$ (Table 4$)$.

\section{Discussions}

The aim of this study was to evaluate whether partial removable denture use indeed leads to improved oral health related quality of life and masticatory function. The present study found that the oral health related quality of life was best in the non-denturegroup than the denture-group $(\mathrm{p}=0.00)$.

The parameters of functional limitation, pain, and physical disability showed a significant difference between both groups of participants, but the non-denture-group were more satisfied with their partial edentulous condition not paired than the denturegroup (Table 2). Our result was similar with other author who showed that the wearing partial removable denture acrylic resin decreased the quality of life of beneficiary [22]. 
Table 2. Oral health impact profile (OHIP).

\begin{tabular}{|c|c|c|c|c|c|}
\hline \multirow[b]{2}{*}{ ITEMS-OHIP-23 } & \multicolumn{2}{|c|}{ Denture-group $(\mathrm{n}=60)$} & \multicolumn{2}{|c|}{ Non denture-group $(\mathrm{n}=78)$} & \multirow[b]{2}{*}{$\mathrm{p}$ value } \\
\hline & $\begin{array}{c}\text { Insatisfaction } \\
(\%)\end{array}$ & $\begin{array}{l}\text { Satisfaction } \\
(\%)\end{array}$ & $\begin{array}{c}\text { Insatisfaction } \\
(\%)\end{array}$ & $\begin{array}{c}\text { Satisfaction } \\
\text { (\%) }\end{array}$ & \\
\hline \multicolumn{6}{|l|}{ 1. Functional limitation } \\
\hline Mastication & $24(40)$ & $36(60)$ & $25(32)$ & $53(68)$ & 0.06 \\
\hline Bad pronounciation & $36(60)$ & $24(40)$ & $51(65)$ & $27(35)$ & 0.03 \\
\hline Affected appearence & $29(49)$ & $31(52)$ & $30(38)$ & $48(62)$ & 0.3 \\
\hline Respiration & $17(28)$ & $43(72)$ & $17(22)$ & $61(78)$ & 0.01 \\
\hline Bad taste & $27(45)$ & $33(55)$ & $16(25)$ & $49(75)$ & 0.3 \\
\hline Affected food intake & $14(23)$ & $46(77)$ & $25(32)$ & $53(68)$ & 0.01 \\
\hline Difficult adaptation & $17(28)$ & $43(72)$ & $48(62)$ & $30(38)$ & 0.01 \\
\hline \multicolumn{6}{|l|}{ 2. Physical pain } \\
\hline Pain in the jaw & $23(38)$ & $37(62)$ & $62(79)$ & $16(21)$ & 0.01 \\
\hline Dental sensibility & $37(57)$ & $26(43)$ & $48(62)$ & $30(38)$ & 0.01 \\
\hline Dental pain & $36(60)$ & $24(40)$ & $49(63)$ & $29(37)$ & 0.04 \\
\hline Pain during the dinner & $25(41)$ & $35(59)$ & $41(53)$ & $37(47)$ & 0.4 \\
\hline \multicolumn{6}{|l|}{ 3. Psychological discomfort } \\
\hline Anxiety/unrest & $20(33)$ & $40(67)$ & $34(44)$ & $44(56)$ & 0.1 \\
\hline Disquiet/miserable unhappy & $20(33)$ & $40(67)$ & $29(37)$ & $49(63)$ & 0.02 \\
\hline Esthetic & $23(38)$ & $37(62)$ & $20(26)$ & $58(74)$ & 0.05 \\
\hline \multicolumn{6}{|l|}{ 4. Physical inability } \\
\hline Unclear speech & $17(28)$ & $43(72)$ & $7(9)$ & $71(91)$ & 0.01 \\
\hline Diminished taste & $33(55)$ & $27(45)$ & $31(40)$ & $47(60)$ & 0.3 \\
\hline Dental brushing & $31(52)$ & $29(48)$ & $18(23)$ & $60(77)$ & 0.3 \\
\hline Food avoidance & $34(57)$ & $26(43)$ & $35(45)$ & $53(55)$ & 0.2 \\
\hline Poor diet & $37(62)$ & $23(38)$ & $45(58)$ & $33(42)$ & 0.3 \\
\hline Not easy at eaten & $28(47)$ & $32(53)$ & $31(40)$ & $47(60)$ & 0.3 \\
\hline Avoid to laugh & $37(62)$ & $23(38)$ & $41(53)$ & $37(47)$ & 0.2 \\
\hline Lack of appetite & $39(65)$ & $21(35)$ & $20(26)$ & $58(74)$ & 0.01 \\
\hline \multicolumn{6}{|l|}{ 5. Discomfort psychological } \\
\hline Stomach upset & $50(83)$ & $10(17)$ & $62(79)$ & $16(21)$ & 0.01 \\
\hline
\end{tabular}

According to [23], the number of pair occluding or functional dental unit plays a very important role in the conservation of the masticatory performance of patients with partial removable denture.

This statement is in agreement with the results of the present study, which showed 
Table 3. Masticatory parameters according to pairs occluding in both groups.

\begin{tabular}{|c|c|c|c|c|c|}
\hline & Occluding pairs & $\begin{array}{c}\mathrm{MaT} \text { (number) } \\
\text { (SD) }\end{array}$ & $\begin{array}{c}\text { MaT (seconds) } \\
\text { (SD) }\end{array}$ & $\begin{array}{c}\mathrm{MaF}(\mathrm{Hz}) \\
\quad(\mathrm{SD})\end{array}$ & $\begin{array}{l}\text { FraS }(\mathrm{mm}) \\
\quad(\mathrm{SD})\end{array}$ \\
\hline & 457 & $119(52.34)$ & $84(34.87)$ & $1.38(0.25)$ & $3.3(3.25)$ \\
\hline \multirow{3}{*}{$\begin{array}{l}\text { Denture-group } \\
\quad(\mathrm{n}=60)\end{array}$} & $0-2$ & $156.20(54.08)$ & $111.17(35.68)$ & $1.42(0.34)$ & $3.3(3.25)$ \\
\hline & $3-5$ & $88.5(22.62)$ & $65.63(13.76)$ & $1.34(0.14)$ & $3.3(3.25)$ \\
\hline & $6-8$ & $83(17.76)$ & $60(8.26)$ & $1.37(0.11)$ & $3.3(3.25)$ \\
\hline \multirow{4}{*}{$\begin{array}{l}\text { Non-denture-group } \\
\qquad(\mathrm{n}=78)\end{array}$} & 390 & $77.9(23.9)$ & $60.2(17.91)$ & $1.29(0.15)$ & $1.5(0.70)$ \\
\hline & $0-2$ & $100(33.29)$ & $82.8(23.91)$ & $1.19(0.08)$ & $1.5(0.70)$ \\
\hline & $3-5$ & $77(11.16)$ & $58.8(11.21)$ & $1.32(0.08)$ & $1.5(0.70)$ \\
\hline & $6-8$ & $64.18(9.08)$ & $51.63(9.33)$ & $1.26(0.18)$ & $1.5(0.70)$ \\
\hline
\end{tabular}

Table 4. Distribution of masticatory parameters in different class of Kennedy.

\begin{tabular}{cccccc}
\hline & Kennedy class & $\begin{array}{c}\text { MaC (Number) } \\
(\mathrm{SD})\end{array}$ & $\begin{array}{c}\text { MaT (seconds) } \\
(\mathrm{SD})\end{array}$ & $\begin{array}{c}\text { MaF (Hz) } \\
(\mathrm{SD})\end{array}$ & $\begin{array}{c}\text { FraS (mm) } \\
(\mathrm{SD})\end{array}$ \\
\hline $\begin{array}{c}\text { Denture group } \\
(\mathrm{n}=60)\end{array}$ & $\mathrm{I}(\mathrm{n}=24)$ & $131.5(60.1)$ & $89.68(26.77)$ & $1.42(0.35)$ & $3.3(3.25)$ \\
& $\mathrm{II}(\mathrm{n}=12)$ & $155.5(66.7)$ & $115.42(49.53)$ & $1.36(0.30)$ & $3.3(3.25)$ \\
& $\mathrm{III}(\mathrm{n}=24)$ & $88.25(17.07)$ & $64.28(10.74)$ & $1.36(0.15)$ & $0.75(0.35)$ \\
\hline $\begin{array}{c}\text { Non-denture group } \\
(\mathrm{n}=78)\end{array}$ & $\mathrm{I}(\mathrm{n}=21)$ & $73(36.1)$ & $37.17(26.35)$ & $1.25(0.12)$ & $1.5(0.70)$ \\
& II (n=18) & $79.5(9.1)$ & $59(3.08)$ & $1.37(0.15)$ & $1.5(0.70)$ \\
& III (n=39) & $67.8(13.1)$ & $54.15(12.82)$ & $1.22(0.17)$ & $1.5(0.70)$ \\
\hline
\end{tabular}

that the participants in the denture-group having at least two functional units had a good masticatory performance than the non-denture-group (Table 3 ). These results are also likewise with the studies of others authors. However, Tsakos G. et al. have reported that the number of occluding pairs is more related to the quality of oral health as the number of natural teeth [24]. In contrary, it was found by Sheiham A. et al. that it was difficult to establish a relationship between intake of nutrients and the number and distribution of teeth in people over 20 natural teeth [25]. They concluded that, the intake of dietary fiber was higher in people with more teeth and significantly associated with the number of occluding pairs. But, it's also been demonstrated by other authors that, the number of occluding pairs units controls the masticatory efficacy [10] [17] [26], which is similar to our results. With gender, a significant difference was found between two groups $(\mathrm{p}=0.02$ and $\mathrm{p}<0.00)$, and men had much higher mastication performance than women (Table 1). These results are similar to those observed in previous studies [27] [28], who reported that the men have higher index efficacy than women.

The number of masticatory cycles in the denture-group was higher than that in the non-denture-group. These results are valid for the gender; age, occluding pairs units and type of classification of Kennedy (Table 1, Table 4). For the same food, the number of cycles before swallowing is characterized by a high inters individual variability 
within the same group of participants. This study shows that the patients in the denture-group work an average of $119.05 \pm 53.70$ cycles before swallowing (Table 3). This variability is also observed in the non-denture-group. The increase in the number of cycles thus appears to be a compensatory mechanism of the mastication disability. These results are similar to those [10] [11] [16] [29]. The variations of the number of cycles can be explained by intrinsic and extrinsic factors. So, depending on the personality, environment and circumstance.

The frequency of mastication in the denture-group was conducted an average of 1.38 $( \pm$ SD 0.25) Hertz and with 1.29 ( \pm SD 0.15) Hertz for the non-denture-group (Table 1). The incidence of mastication was higher in the denture-group. Those results are similar to the studies of Bessadet M et al. and study of Sanchez-Ayala Aetal [10] [30].

Hope to have a larger size of sample and from different regions than used in this study and the changes addresses and telephone numbers of patients, and a few deaths cases were among the limitations of our work.

\section{Conclusion}

There are significant differences in oral health related quality of life between the denture and the non-denture group. The overall oral health related quality of life was satisfied in the non-denture than denture. Denture wearing participant displayed significantly more mastication cycles and needed more mastication time, which resulted in significantly smaller peanut fragment sizes compared to the non-denture wearing participants.

\section{Acknowledgements}

The authors would like to thank Pr. Dr. Fons Verdonck, Frans Vinckier, Mvumvi Le lo and Dr. Phillippe Vuylesteke from KU Leuven University and from Kinshasa University for their relevant scientific contribution and financial.

\section{Conflict of Interest}

The authors confirm that this article content has no conflict of interest.

\section{References}

[1] Azerad, J. (1992) Physiologie de la manducation. 1ère Edition, 1-116.

[2] Barbato, P.R. and Peres, M.A. (2009) Tooth Loss and Associated Factors in Adolescents: A Brazilian Population-Based Oral Health Survey. Revista de Saúde Pública, 43, 13-25.

[3] Van Der Bilt, A. (2011) Assessment of Mastication with Implications for Oral Rehabilitation. Review. Journal of Oral Rehabilitation, 38, 754-780. http://dx.doi.org/10.1111/j.1365-2842.2010.02197.x

[4] Levin, B. (1974) Editorial: The 28-Tooth Syndrome or Should All Teeth Be Replaced? Dental Survey, 50, 47.

[5] Kayser, A.F. (1981) Shortened Dental Arches and Oral Function. Journal of Oral Rehabilitation, 8, 457-462. http://dx.doi.org/10.1111/j.1365-2842.1981.tb00519.x 
[6] Gotfredsen, K. and Walls, A.W. (2007) What Dentition Assures Oral Function? Clinical Oral Implants Research, 18, 34-45. http://dx.doi.org/10.1111/j.1600-0501.2007.01436.x

[7] Kanno, T. and Carlsson, G.E. (2006) A Review of the Shortened Dental Arch Concept Focusing on the Work by the Kayser/Nijmegen Group. Journal of Oral Rehabilitation, 33, 850-862. http://dx.doi.org/10.1111/j.1365-2842.2006.01625.x

[8] Gerritsen, A.E., Witter, D.J., Bronkhorst, E.M. and Creugers, N.H. (2013) Increased Risk for Premolar Tooth Loss in Shortened Dental Arches. Journal of Dentistry, 41, 726-731. http://dx.doi.org/10.1016/j.jdent.2013.05.013

[9] Ikebe, K., Hazeyama, T., Kagawa, R., Matsuda, K. and Maeda, Y. (2010) Maeda Subjective Values of Different Treatments for Missing Molars in Older Japanese. Journal of Oral Rehabilitation, 37, 892-899. http://dx.doi.org/10.1111/j.1365-2842.2010.02123.x

[10] Bessadet, M., Nicolas, E., Sochat, M., Hennequin, M. and Veyrune, J.L. (2013) Impact of Removable Partial Denture Prosthesis on Chewing Efficiency. Journal of Applied Oral Science, 21, 392-396.

[11] Mishellany, A., Woda, A., Labas, R. and Peyron, M.A. (2006) The Challenge of Mastication: Preparing a Bolus Suitable for Deglutition. Dysphagia, 21, 87-94. http://dx.doi.org/10.1007/s00455-006-9014-y

[12] Moynihan, P., Thomson, M., Walls, A., et al. (2009) Researching the Impact of Oral Health and Diet and Nutritional Status: Methological Issues. Journal of Dentistry, 37, 237-249. http://dx.doi.org/10.1016/j.jdent.2008.12.003

[13] Gunji, A., Kimoto, S., Koide, H., Murakami, H., Matsumaru, Y., Kimoto, K., et al. (2009) Investigation on How Renewal of Complete Dentures Impact on Dietary and Nutrient Adequacy in Edentulous Patients. Journal of Prosthodontic Research, 53, 180-184. http://dx.doi.org/10.1016/j.jpor.2009.06.001

[14] Kumpanya, P.N., Mantshumba, M.A., Sekele, I.B., Mayunga, M., Lutula, P.S. and Ntumba, M.K. (2015) Syndrome ectodermique de cap de pont et réhabilitation orale prothétique. A propos d'un cas clinique. Odonto-Stomatologie Tropicale, 38, 43-45.

[15] Jepson, N.J., Moynihan, P.J., Kelly, P.J., Watson, G.W. and Thomason, J.M. (2001) Caries Incidence Following Restoration of Shortened Lower Dental Arches in a Randomized Controlled Trial. British Dental Journal, 191, 140-144.

[16] Liang, S., Zhang, Q., Witter, D.J., Wang, Y. and Greugers, N.H.J. (2015) Effects of Removable Dental Prostheses on Masticatory Performance of Subjects with Shortened Dental Arches: A Systematic Review. Journal of Dentistry, 43, 1185-1194. http://dx.doi.org/10.1016/j.jdent.2015.05.008

[17] Veyrune, J.L., Tubert-Jeannin, S., Dutheil, C. and Riordan, P.J. (2005) Impact of New Prostheses on the Oral Health Related Quality of Life of Edentulous Patients. Gerodontology, 22, 3-9. http://dx.doi.org/10.1111/j.1741-2358.2004.00048.x

[18] Sekele, I.B., et al. (2016) Influence de la Prothèse amovible Partielle en résine acrylique sur la santé bucco-dentaire et la qualité de vie. Odonto-Stomatologie Tropicale, 39, 36-45.

[19] Mantshumba, M.A., Duyck, J., Sekele, I.B., Lutula, P.S., Nyimi, B.F., Bile, B.G., Sofi, N.P., Kalala, E.K., Ekofo, I.E., Kumpanya, N.P., Mayunga, M., Ntumba, M.K. and Naert, I. (2016) Risks Factors of Caries and Periodontal Diseases in Patients, after 5 Years Use a Partial Removable Denture. Open Journal of Stomatology, 6, 185-192. http://dx.doi.org/10.4236/ojst.2016.68024

[20] Slade, G.D., Spencer, A.J. and Roberts-Thomson, K. (1996) Tooth Loss and Chewing Capacity among Older Adults in Adelaide. Australian and New Zealand Journal of Public Health, 20, 76-82. http://dx.doi.org/10.1111/j.1467-842X.1996.tb01341.x 
[21] Yengopal W, Naidoo S. (2008) Do Oral Lesions Associated with HIV Affect Quality of Life? Oral Surgery, Oral Medicine, Oral Pathology, Oral Radiology and Endodontics, 106, 66-73. http://dx.doi.org/10.1016/j.tripleo.2007.12.024

[22] Lahti, S., Suominen, T. and Hausen, H. (2008) Oral Health Impacts among Adults in Finland: Competing Effects of Age, Number of Teeth, and Removable Dentures. European Journal of Oral Sciences, 116, 260-266. http://dx.doi.org/10.1111/j.1600-0722.2008.00540.x

[23] Yamashita, S., Sakai, S., Hatch, J.P. and Rugh, D. (2000) Relationship between Oral Function and Occlusal Support in Denture Wearers. Journal of Oral Rehabilitation, 27, 881-886.

[24] Tsakos, G., Marcenes, W. and Sheiham, A. (2004) The Relationship between Clinical Dental Status and Oral Impacts in an Elderly Population. Oral Health \& Preventive Dentistry, 2, 211-220.

[25] Sheiham, A. and Steele, J. (2001) Does the Condition of the Mouth and Teeth Affect the Ability to Eat Certain Foods, Nutrient and Dietary Intake and Nutritional Status amongst Older People? Public Health Nutrition, 4, 797-803. http://dx.doi.org/10.1079/PHN2000116

[26] Decerle, N., Nicolas, E. and Hennequin, M. (2013) Chewing Deficiencies in Adults with Multiple Untreated Carious Lesions. Caries Research, 47, 330-337. http://dx.doi.org/10.1159/000348397

[27] Witter, D.J., Cramwinckel, A.B., Van Rossum, G.M. and Kayser, A.F. (1990) Shortened Dental Arches and Masticatory Ability. Journal of Dentistry, 18, 185-189. http://dx.doi.org/10.1016/0300-5712(90)90107-P

[28] Akeel, R., Nilner, M. and Nilner, K. (1992) Masticatory Efficiency in Individuals with Natural Dentition. Swedish Dental Journal, 16, 191-198.

[29] Ueda, T., Sakurai, K. and Sugiyama, T. (2006) Individual Difference in the Number of Chewing Strokes and Its Determinant Factors. Journal of Oral Rehabilitation, 33, 85-93. http://dx.doi.org/10.1111/j.1365-2842.2006.01537.x

[30] Sanchez-Ayala, A., Farias-Neto, A., Campanha, N.H., Matheus, R.C. and Garcia, R. (2013) Relationship between Chewing Rate and Masticatory Performance. The Journal of Craniomandibular \& Sleep Practice, 31, 118-122. http://dx.doi.org/10.1179/crn.2013.019

\section{Submit or recommend next manuscript to SCIRP and we will provide best service for you:}

Accepting pre-submission inquiries through Email, Facebook, LinkedIn, Twitter, etc. A wide selection of journals (inclusive of 9 subjects, more than 200 journals)

Providing 24-hour high-quality service

User-friendly online submission system

Fair and swift peer-review system

Efficient typesetting and proofreading procedure

Display of the result of downloads and visits, as well as the number of cited articles

Maximum dissemination of your research work

Submit your manuscript at: http://papersubmission.scirp.org/

Or contact ojst@scirp.org 